\title{
A Comprehensive Review on Pixel Oriented and Object Oriented Methods for Information Extraction from Remotely Sensed Satellite Images with a Special Emphasis on Cryospheric Applications
}

\author{
Shridhar D. Jawak1, Prapti Devliyal2', Alvarinho J. Luis ${ }^{1}$ \\ ${ }^{1}$ Earth System Science Organization (ESSO), National Centre for Antarctic \& Ocean Research (NCAOR), \\ Ministry of Earth Sciences, Government of India, Vasco da Gama, India \\ ${ }^{2}$ Department of Civil Engineering, Symbiosis Institute of Technology, Symbiosis International University, Pune, \\ India \\ Email: shridhar.jawak@ncaor.gov.in, praptid.90@gmail.com, alvluis@ncaor.gov.in
}

Received 22 May 2015; accepted 20 July 2015; published 23 July 2015

Copyright (C) 2015 by authors and Scientific Research Publishing Inc.

This work is licensed under the Creative Commons Attribution International License (CC BY). http://creativecommons.org/licenses/by/4.0/

(c) (1) Open Access

\section{Abstract}

Image classification is one of the most basic operations of digital image processing. The present review focuses on the strengths and weaknesses of traditional pixel-based classification (PBC) and the advances of object-oriented classification (OOC) algorithms employed for the extraction of information from remotely sensed satellite imageries. The state-of-the-art classifiers are reviewed for their potential usage in urban remote sensing (RS), with a special focus on cryospheric applications. Generally, classifiers for information extraction can be divided into three catalogues: 1 ) based on the type of learning (supervised and unsupervised), 2) based on assumptions on data distribution (parametric and non-parametric) and, 3) based on the number of outputs for each spatial unit (hard and soft). The classification methods are broadly based on the PBC or the OOC approaches. Both methods have their own advantages and disadvantages depending upon their area of application and most importantly the RS datasets that are used for information extraction. Classification algorithms are variedly explored in the cryosphere for extracting geospatial information for various logistic and scientific applications, such as to understand temporal changes in geographical phenomena. Information extraction in cryospheric regions is challenging, accounting to the very similar and conflicting spectral responses of the features present in the region. The spectral responses of snow and ice, water, and blue ice, rock and shadow are a big challenge for the pixel-based classifiers. Thus, in such cases, $00 \mathrm{C}$ approach is superior for extracting information from the cryospheric regions. Also, ensemble classifiers and customized spectral index ratios 
(CSIR) proved extremely good approaches for information extraction from cryospheric regions. The present review would be beneficial for developing new classifiers in the cryospheric environment for better understanding of spatial-temporal changes over long time scales.

\section{Keywords}

\section{Pixel Based Classification, Object Oriented Classification, Cryosphere, Antarctica}

\section{Introduction}

Image classification is one of the most basic operations of digital image processing (DIP). In most simple terms, image classification can be expressed as the process of distributing image into classes or categories of the analogous type. Digital image classification is the process of assigning pixels to meaningful classes [1]. It is a computer-assisted analysis of images for consequential information extraction. Thus, classification can also be termed as information extraction. A pixel is assumed to be an individual unit which carries several spectral band values. The pixels of an image having comparable spectral values are assigned to one class. Classes are homogenous; thus pixels of one class differ spectrally with the pixels of another class of the same image. These classes form regions on a map or an image, so that after classification the digital image can be presented as a mosaic of consistent classes, each identified by a color or symbol (Figure 1) [1].

In the field of RS, numerous attempts have been made for developing an effective approach for the information extraction processes. The availability of a range of high resolution (HR) images offers an advantage for more precise extraction of information by developing advanced classification schemes. RS classification is a complex process and requires consideration of many factors. According to Lu and Weng [2], the major steps of image classification include: 1) choice of a suitable classification system, 2) selection of training samples, 3) image preprocessing and feature extraction, 4) selection of suitable classification methods, 5) post-classification processing, and 6) accuracy assessment.

Comprehensive review of information extraction techniques and algorithms has not been done much, though there are lots of research attempts that are aimed at image classification [2]-[4]. Lu and Weng [2] performed a review of image classification methods and techniques for improving classification performance. The authors examine current practices, problems, and prospects of image classification and summarize major advanced classification approaches and techniques that are used for improving classification accuracy. Recently, Kumar and Singh [5] reviewed DIP techniques for information extraction from HR satellite images. Insightful efforts have been made in developing advanced classification algorithms and techniques for improving the accuracy of

\begin{tabular}{|l|l|l|l|l|l|l|l|}
\hline 1 & 9 & 6 & 3 & 1 & 0 & 6 & 8 \\
\hline 0 & 7 & 7 & 2 & 8 & 7 & 9 & 6 \\
\hline 2 & 5 & 6 & 1 & 2 & 9 & 8 & 7 \\
\hline 0 & 2 & 8 & 3 & 1 & 0 & 2 & 4 \\
\hline 2 & 9 & 7 & 2 & 9 & 4 & 7 & 5 \\
\hline 2 & 8 & 7 & 0 & 1 & 3 & 5 & 7 \\
\hline 6 & 0 & 6 & 9 & 8 & 7 & 7 & 9 \\
\hline 8 & 9 & 5 & 6 & 5 & 6 & 9 & 5 \\
\hline
\end{tabular}

(a)

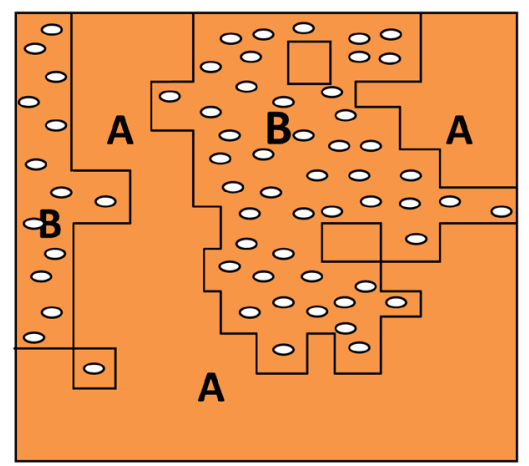

(b)

Figure 1. (a) Numeric image and (b) classified image. According to the numeric values, the image has been classified into two classes A and B. The pixels with similar spectral values are assigned to one class. Thus, class $A$ is the one having bright pixel values $(5,6,7,8$ and 9$)$ and class $\mathrm{B}$ is the one having dark pixel values $(0,1,2,3$ and 4$)$. There can be more than two classes and at least three or four spectral bands. 
classification [6]-[14].

Arbiol et al. [15] presented a review of the image classification techniques, focusing especially on advanced classification methods. Many researchers have reviewed information extraction algorithms focusing on a specific classification technique or techniques that are used for extraction of a definite feature from the image [16][18]. With the advent of HR and very-high resolution (VHR) RS imagery [19] [20] like IKONOS, QuickBird (QB) and World View-2 (WV-2), OOC methods are recently gaining the interest of the researchers [21]-[23]. OOC methods group a number of pixels with homogeneous properties into an object and objects, instead of pixels, are considered the basic unit for analysis [24]. However, successful classification of RS data is an enormous challenge because many factors pertaining to the appropriate selection of RS data, image pre-processing and processing methods (especially image classification strategies) and also the complexity of landscape in study areas may result in inappropriate results. With the continuous evolution of the RS and geographical information system (GIS) field in recent years, more and more researchers are now interested in exploring this technology for information extraction from satellite imageries rapidly. This necessitated a detailed compilation of information extraction algorithms which would be exceptionally valuable for the researchers who are new to the field of HR RS, in selecting appropriate classification technique for a specific study. The focus of this paper is on summarizing all the possible information extraction techniques that are available till date for extracting information from HR satellite data with their practicability for cryospheric applications.

\section{Information Extraction Procedures}

Broadly, classifiers for information extraction can be divided into three catalogues: 1) based on the type of learning (supervised and unsupervised), 2) based on assumptions on data distribution (parametric and non-parametric) and, 3) based on the number of outputs for each spatial unit (hard and soft). Figure 2 is the representation of basic categorization of the classifiers, according to our understanding. Also, we have discussed the procedure for some of the important classification techniques that are useful in information extraction.

\subsection{Unsupervised and Supervised Classification}

The identification of natural groups, or structures, within multi-spectral (MS) data, is termed as unsupervised classification. It does not require training data as the basis for classification. These classifiers try to combine reflectance pixel values in the feature space, into substantially separated clusters which are considered as classes. After spectral grouping, the analyst identifies the obtained classes to some form of reference data. Thus, in unsupervised classification procedure: 1) training datasets are not required and 2) only a specification of number of classes is required by the user. Several clustering algorithms exist that can be used to verify the natural spectral clusters present in the image. The most popular classifiers which use this algorithm are $K$-means and iterative self-organizing data analysis (ISODATA). Change detection is one of the main applications for such methods, where the method recognizes the changes in real time. Unlike unsupervised classification, the supervised classification method uses training samples of known identity (ground reference sites) to classify pixels of unknown identity (i.e., unclassified pixels are assigned to one of the several informational classes). The supervised classification algorithm is the demonstration of sample sites of known cover type, called training sites, which are used to establish a numerical interpretation key that describes the spectral attributes for each feature type of interest. Then the reflectance value of each pixel is compared numerically to each class with the interpretation key marked with the name of the class it matches most similar to in the image. In this, the user defines the decision rules for each class directly or provides training data for each class to assist the computer classification. Here, labeled information is used to train a model capable of recognizing the pre-defined classes. Thus, in supervised classification procedure; 1 ) the decision rules for each class are defined directly and 2) training data (class prototypes) for each class are provided to assist the classification. Major steps involved in supervised and unsupervised classification are depicted in Figure 3.

There are three major steps involved in the classic supervised classification, 1) training: the user identifies representative training areas or samples and develops a numerical description of the spectral attributes (spectral signature) of each land cover class of interest in the image, 2) classification: each pixel in the image is classified into the land cover class based on its resemblance to the input training pixel and if the pixel is not matching to any predefined class signature then it is classified as unknown or unclassified, and 3) accuracy assessment: the classified thematic image is compared with reference image or ground reference data to check the accuracy of the 


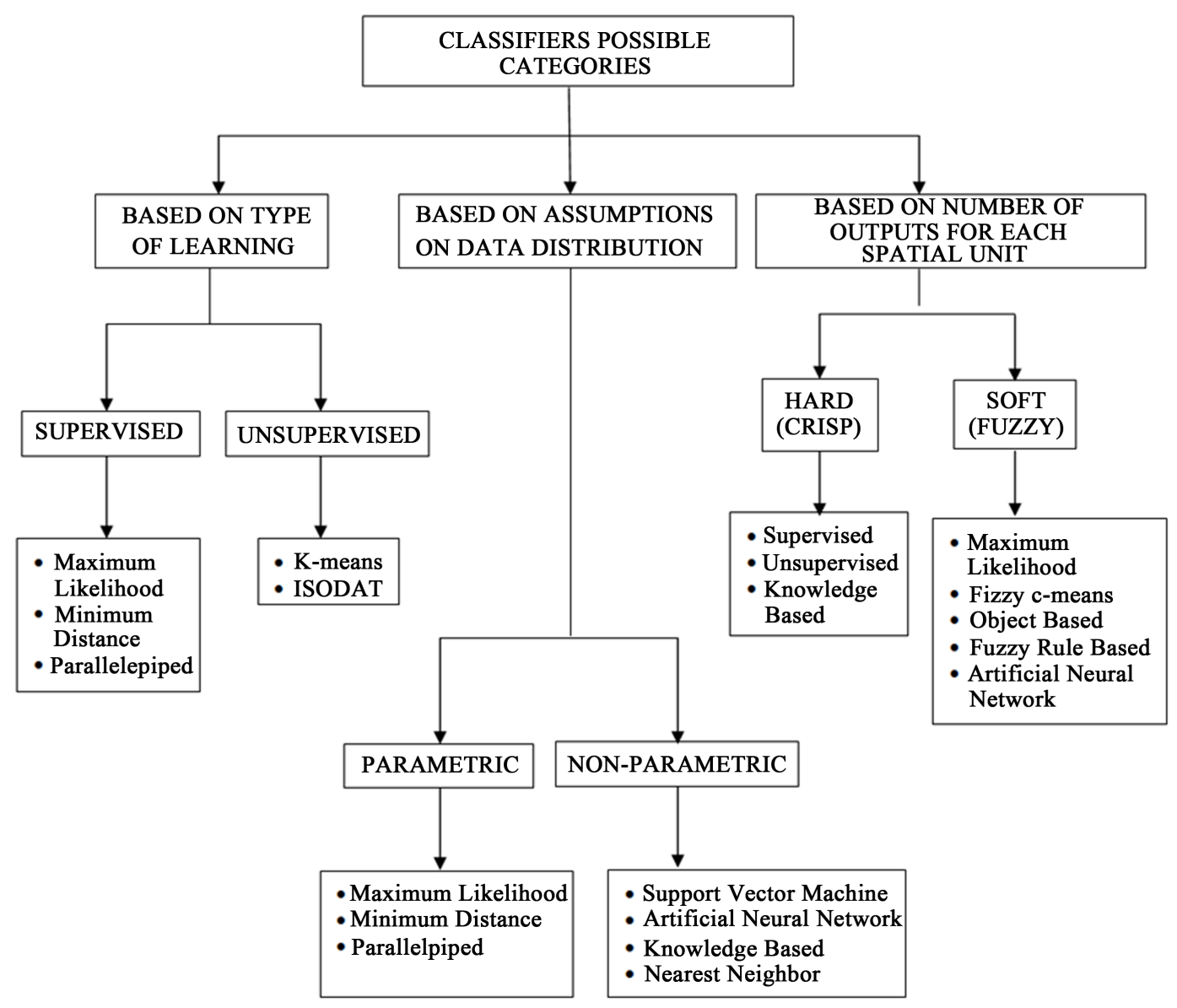

Figure 2. Categorization of classifiers.
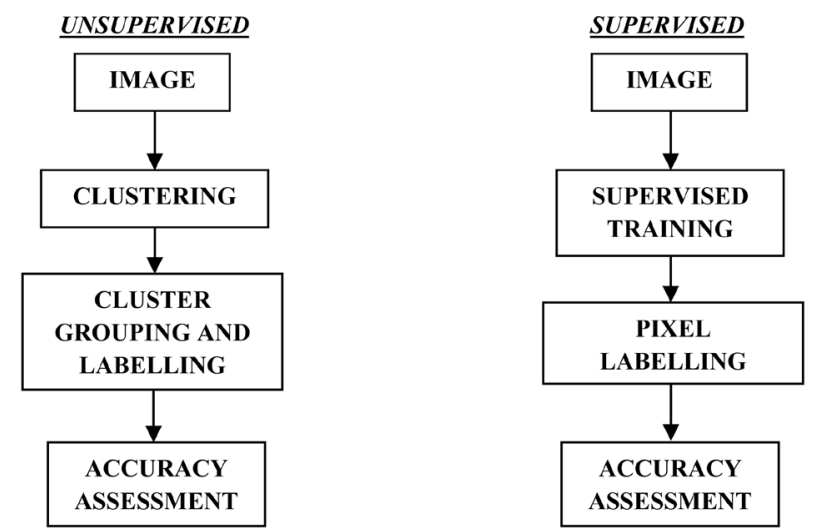

Figure 3. Major steps involved in unsupervised and supervised image classification.

classification. There are several classifiers that fall under the category of supervised classification. The most popular classifiers are maximum likelihood classifier (MXL), Mahalanobis distance (MhD), support vector machines (SVMs), spectral angle mapper (SAM), parallelepiped (PP), and minimum distance (MD).

\subsection{Pixel- and Object-Based Classification}

PBC is considered as the typical method for classification of RS images, which is based on conventional statis- 
tical techniques such as supervised and unsupervised classification. The traditional PBC process automatically categorizes all the pixels of an image into the thematic classes utilizing only the spectral information (relative reflectance) of each pixel in the image. The spectral information used by each pixel is also termed as a spectral signature, which is estimated by the relative reflectance in different wavelength bands. Pixel-based approach for classification of RS imagery is at present limited to HR data, such as QB images, as they produce some undesirable classification results in extracting the targeted class. To overcome the limitation of the PBC approach in HR RS, OOC approach was suggested in which the processing units are no longer single pixel, but it is an image object.

Geographic object-based image analysis (GEOBIA) has been gaining importance e in all the fields of RS over the past decade, especially to take an advantage of spatial-spectral characteristics of the high resolution satellite data for information extraction. Since the emergence of fine spatial resolution satellite sensor imagery, OOC has been applied comprehensively to overcome the within-object variation that can lead to pixel-based misclassification. Literature review of the OOC approaches in RS has suggested that the rule-based classifier and the standard nearest neighbor (NN) classifier are among the most commonly employed object classifiers, popularized by the availability of commercial software such as e Cognition and ENVI. OOC approach utilizes image segmentation and fuzzy classification on the results of segmentation. Broadly, this process can be divided into two main workflow steps: 1) multi-resolution segmentation and, 2) knowledge-based classification of the segments. In general, OOC algorithm initially performs segmentation of the whole image into consequential pixel groups that are referred to as segments. Then the user defines a set of knowledge-based classification rules (spectral, spatial, contextual and textual information) to describe each class. Thereafter, the classifier is chosen to assign each segment to the proper class according to a defined set of rules. Table 1 shows the attributes used in PBC and OOC approaches.

\subsection{Hybrid Classification}

Hybrid classification approach fuses the elements of supervised and unsupervised algorithms. Since early 1990s, several hybrid methods have also been tried and refined in many cases to improve classification accuracy. Hybrid methods have demonstrated significant results in analyses where there is complex variability in the spectral data within information classes. The algorithm of most hybrid methods involves: 1) initial arrangement of the imagery by spectral clustering, 2) assigning clusters to user-defined classes, and 3) classification of the entire image using supervised learning. The Iterative Guided Spectral Class Rejection (IGSCR) is one such hybrid classifier which uses specific rejection criteria and large numbers of training pixels to cluster analogous pixels into two or three user-defined classes through a sequence of iterations. This method accepts and labels a spectral class if it meets user defined inclusion threshold and rejects it if it does not. Until a convergence threshold is met, rejected pixels continue to be classified in the next iteration and so on. At the end, the supervised decision rule is used to classify the image into pre-defined information classes utilizing these pure classes.

\subsection{Decision Tree (DT)}

DT is a classifier network in which the compilation of simple classifiers is made to solve a complex problem in classification. It is a hierarchical configuration, where at each level, a test is employed to one or more attribute

Table 1. Attributes used in PBC and OOC approaches.

\begin{tabular}{|c|c|c|}
\hline \multirow[t]{2}{*}{ Attributes } & \multicolumn{2}{|c|}{ Classification Approach } \\
\hline & Pixel Based & Object Based \\
\hline Spectral/Color & Used & Used \\
\hline Form/Shape & Not-Used & Used \\
\hline Area/Size & Not-Used & Used \\
\hline Texture & Not-Used & Used \\
\hline Content & Not-Used & Used \\
\hline
\end{tabular}


values that may have one of the two outcomes. The outcome may be a leaf of DT, which defines a class, or a decision node, which signifies a further test on the attribute values and forms a branch or sub-tree of the tree. The algorithm for constructing a DT is summarized below:

- If there are $\boldsymbol{k}$ classes represented by $\{$ Class $\mathbf{1}$, Class2,..., Classk $\}$, and a training set, $T$, then

- If $T$ contains one or more objects which all belong to a single class Classj, then the DT is a leaf identifying class Classj.

- If $T$ contains no objects, the DT is a leaf determined from information other than $T$.

- If $T$ contains objects that belong to a mixture of classes, then a test is chosen, based on a single attribute that has one or more mutually exclusive outcomes $\{$ Object1, Object2..., Objectn $\} . T$ is partitioned into subsets $T \mathbf{1}$, $T 2 \ldots, T n$, where $T \mathbf{i}$ contains all the objects in $T$ that have outcome Objecti of the chosen test. The similar method is applied recursively to each subset of training objects to build the DT.

DT classifiers vary in ways they partition the training sample into subsets and thus form sub-trees, i.e. DTs differ in their criteria for evaluating splits into subsets. Information theory is used by the induction algorithm to evaluate splits. Many studies have been done comparing DT algorithm with other classifiers and found that based on the information theory, it is more accurate and gives reliable results. The other advantage of the algorithm is that it can convert DT into corresponding classification rules. Rules are more comprehensive, easy to understand and easy to implement.

\subsection{Artificial Neural Networks (ANN)/Neural Network Classifier (NNC)}

The computer programs or rule sets that are targeted to simulate human learning processes through the establishment and reinforcement of linkages between input data and output data are called ANNs. The basic element of ANNs is the processing node that corresponds to the neuron of the human brain. Each processing node receives and sums a set of input values, and passes this sum through an activation function providing the output value of the node, which in turn forms one of the inputs to a processing node in the next layer of ANNs. When considering the use of the NNC approach to classification, it is necessary to make several key decisions beforehand. First, the number of layers to use must be chosen. Commonly, a three-layer network is sufficient, with the purpose of the first layer being simply to allocate the components of the input pixel vector to each of the processing elements in the second layer. The next choice relates to the number of elements in each layer. The input layer will usually be given as many nodes as there are features in the pixel vectors. The number to use in the output node will depend on how the outputs are used to represent the classes. The simplest method is to let each separate output signify a different class, in which case the number of output processing elements will be the same as the number of training classes. ANNs are composed of three elements (Figure 4):

1) An input layer consists of the source data, which in the context of RS are the MS observations, perhaps in several bands and from several dates. ANNs are designed to work with large volumes of data, including many bands and dates of MS observations, together with related ancillary data.

2) The output layer consists of the classes required by the user. There are few restrictions on the nature of the output layer, although the process will be more consistent when the number of output labels is small or modest with respect to the number of input channels. Included are training data in which the association between output labels and input data is clearly established.

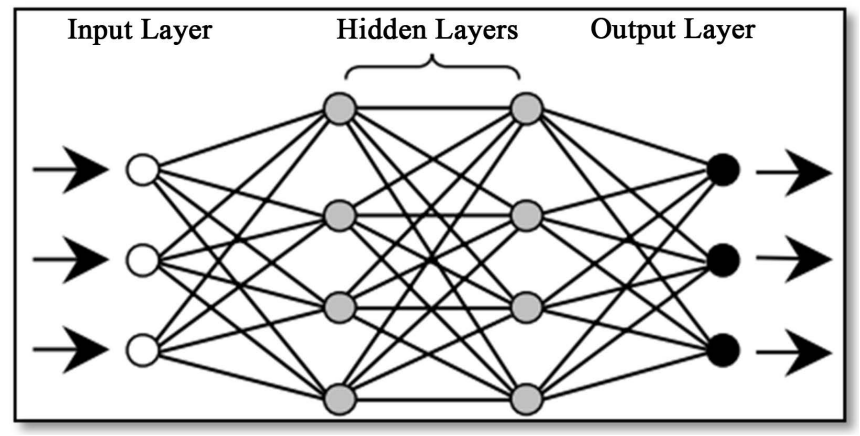

Figure 4. A simple four layer feed-forward neural network (Source: Cetin et al. [25]). 
3) During the training phase, an ANN establishes a connection between input and output data by establishing weights within one or more hidden layers. In the context of RS, repeated associations between classes and digital values, as expressed in the training data, strengthen weights within hidden layers that permit the ANN to assign correct labels when given spectral values in the absence of training data.

\subsection{Ensemble}

Ensemble learning refers to a collection of methods that learn a target function by training a number of individual classifiers and combining their predictions. The key idea of ensemble methodology is to combine a set of models, each of which solves the same original task, in order to obtain an improved composite global model, with more accurate and reliable estimates or decisions than those, which can be obtained from using a single model. Ensemble methods can be also used for improving the robustness of clustering algorithms. Formation of an ensemble involves: 1) modifying the data 2) modifying the learning task 3) exploiting the algorithm characteristics, and 4) exploiting problem characteristics. Methods for independently constructing ensembles are: 1) majority vote, 2) bagging and random forest (RF), 3) randomness injection, 4) feature-selection, and 5) error-correcting output coding. Methods for coordinated construction of ensembles are: 1) boosting, and 2) stacking. The way of combining the classifiers may be divided into two main groups: 1) simple multiple classifier combinations and 2) meta-combiners. The simple fusing methods are best suited for problems where the individual classifiers perform the same task and have comparable success. However, such combiners are more vulnerable to outliers and unevenly performing classifiers. Simple combining methods are uniform voting, distribution summation, Bayesian combination, Dempster-Shafer, Naïve Bayes, Bayesian Augmented Naïve Bayes (BAN) and Naïve Bayes Classifiers (NBC), entropy weighting, density-based weighting, and logarithmic opinion pool. On the other hand, the meta-combiners are theoretically more powerful but are susceptible to all the problems associated with the added learning (such as over-fitting, long training time). Meta-learning means learning from the classifiers produced by the inducers and from the classifications of these classifiers on training data. Meta-combining methods are stacking, arbiter trees, combiner trees, and grading. Based on our literature review, we have compiled case studies which involve the application of different classifiers in RS studies and depicted them in Table 2, whereas Table 3 shows the comparative study of classifiers used in different studies.

\subsection{Sub-Pixel Classification}

RS images captured by low, medium, and coarse spatial resolutions, are contaminated with mixed pixels that represent more than one class on the ground. Hard classification process may result in an erroneous classification of images crowded with mixed pixels. This may be because of the fact that the spectral signature of a mixed pixel may no longer match any of the component classes or may be similar to the spectral signature of a different class. Therefore, allocating a mixed pixel to only one class may not be desirable because of the loss of pertinent class information associated within the mixed pixels. Therefore, to overcome the presence of mixed pixels in images, methods have been developed which quantitatively decompose or unmix the mixed pixels into its class components. This process is called sub-pixel classification, which has also been referred as spectral unmixing, spectral decomposition, fuzzy classification, and soft classification. The sub-pixel classification process decomposes a collection of class component spectra or endmembers. Thus, sub-pixel classification methods tend to resolve a pixel into various class components, generating many outputs in the form of fraction images. There are two main types of sub-pixel classification procedures: 1) based on linear models and 2) based on non-linear models.

\section{Pixel-Based versus Object-Based Classification}

OOC has shown many advantages over PBC especially in HR RS [45]. Traditional PBC methods are all based on grey value or digital number (DN) value of a pixel and thus only spectral information can be used for classification purpose. At present PBC approach is limited for HR data, e.g. QB images, as they are unable to produce appropriate results in extracting the targeted objects. OOC approach can overcome this problem as it utilizes image segmentation and fuzzy classification on the results of segmentation. Unlike PBC approach, the processing unit is not a single pixel, but an entire image object. Also as compared to PBC approach which utilizes only spectral response, image object in OOC approach contains additional information such as object texture, 
Table 2. Tabular representation of classifiers used in different studies.

\begin{tabular}{|c|c|c|c|c|}
\hline $\begin{array}{l}\text { Satellite } \\
\text { Image }\end{array}$ & $\begin{array}{l}\text { Study Area } \\
\text { (Application) }\end{array}$ & Classifiers & Classes & Accuracy/Results \\
\hline $\begin{array}{l}\text { Geo Eye-1 } \\
\text { (GE1) [26] }\end{array}$ & $\begin{array}{l}\text { Beijing, China. } \\
\text { (Land use/cover) }\end{array}$ & BAN and NBC & $\begin{array}{c}5 \text { [Houses, Roads, Grass, Hills, } \\
\text { and Rivers] }\end{array}$ & $\begin{array}{l}\text { BAN-86.2\% } \\
\text { NBC-82.0\% }\end{array}$ \\
\hline $\begin{array}{c}\text { GE-1 and } \\
\text { QB } \\
{[27]}\end{array}$ & $\begin{array}{l}\text { Fredericton, Canada. } \\
\text { (Land use Land cover) }\end{array}$ & $\begin{array}{l}\text { Fuzzy method } \\
\text { (FM) and Crisp } \\
\text { method (CM) }\end{array}$ & $\begin{array}{l}5 \text { [Shadow, vegetation, road, } \\
\text { building and bare land] }\end{array}$ & $\begin{array}{c}\text { FM (GE-1)-82\% } \\
\text { FM(QB)-90\% } \\
\text { CM (GE-1)-68\% } \\
\text { CM (QB)- } 42 \%\end{array}$ \\
\hline $\begin{array}{l}\text { GE-1 and } \\
\text { WV-2 } \\
{[28]}\end{array}$ & $\begin{array}{l}\text { Cuevas del Almanzora, } \\
\text { southern Spain } \\
\text { (Land cover } \\
\text { classification) }\end{array}$ & $\begin{array}{l}\text { OOC-NNC } \\
\text { and SVM }\end{array}$ & 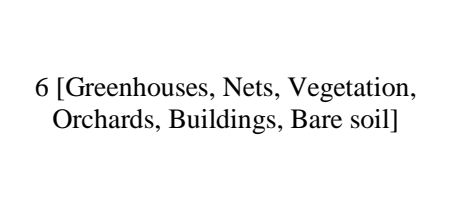 & $\begin{array}{c}\text { NNC (GE-1)-87.91\% } \\
\text { SVM (GE-1)-85.71\% } \\
\text { NNC (WV-2_4)-89.01\% } \\
\text { SVM (WV-2_4)-84.07\% } \\
\text { NNC (WV-2_8)-87.91\% } \\
\text { SVM (WV-2_8)-87.36\% }\end{array}$ \\
\hline $\begin{array}{c}\text { IKONOS } \\
{[29]}\end{array}$ & $\begin{array}{l}\text { Ghent in Belgium } \\
\text { (Urban land } \\
\text { cover mapping) }\end{array}$ & $\begin{array}{l}\text { Ensemble } \\
\text { Classifiers-DT, } \\
\text { ANN, and RF. }\end{array}$ & $\begin{array}{l}9 \text { [water, grass, trees, buildings (with } \\
\text { dark roof, red roof, bright roof), roads, } \\
\text { other man-made objects, shadow] }\end{array}$ & $\begin{array}{l}\text { Results indicate that ensemble } \\
\text { classifiers generate significantly } \\
\text { higher accuracies than } \\
\text { a single classifier. }\end{array}$ \\
\hline $\begin{array}{c}\text { IKONOS } \\
{[30]}\end{array}$ & $\begin{array}{c}\text { Pico da Vara } \\
\text { Natural Reserve. } \\
\text { (Vegetation mapping) }\end{array}$ & $\begin{array}{l}\text { SVM, ANN, MhD } \\
\text { and MXL } \\
\text { (parametric } \\
\text { methods) }\end{array}$ & $\begin{array}{l}8 \text { [Forestry production species, } \\
\text { aggressive alien invasive species, } \\
\text { bare soil areas, clouds, natural } \\
\text { pasture areas and shadows of clouds] }\end{array}$ & $\begin{array}{l}\text { Despite the poor separability of } \\
\text { some vegetation categories, MXL, } \\
\text { SVM and ANN classifications } \\
\text { have achieved good overall } \\
\text { accuracies (overall accuracy }>75 \% \\
\text { and Kappa Index Agreement }>0.6 \text { ) }\end{array}$ \\
\hline $\begin{array}{l}\text { QB } \\
{[31]}\end{array}$ & $\begin{array}{l}\text { Brandenburg, } \\
\text { Germany. } \\
\text { (Forest types) }\end{array}$ & $\begin{array}{l}\text { Knowledge-based } \\
\text { methods }\end{array}$ & $\begin{array}{l}5 \text { [Pine, Larch, Beech, } \\
\text { Robinia and Oak] }\end{array}$ & $\begin{array}{l}\text { Results show a good separability } \\
\text { with approximately } 80 \% \text { to } 90 \% \\
\text { overall accuracy for the tree species } \\
\text { beech, oak, robinia, larch, and pine. }\end{array}$ \\
\hline $\begin{array}{l}\text { QB } \\
{[32]}\end{array}$ & $\begin{array}{l}\text { Lang Tengah Island. } \\
\text { (Coral distribution } \\
\text { mapping) }\end{array}$ & $\begin{array}{c}\text { Ensembles } \\
\text { classifier-PP, MD, } \\
\text { MXL, Fisher and } \\
\text { K-Nearest } \\
\text { Neighbor (NN) }\end{array}$ & $\begin{array}{l}4 \text { [Dense coral, Sparse Coral, } \\
\text { Dead Coral and Sand] }\end{array}$ & $\begin{array}{l}\text { Using an ensemble classification } \\
\text { approach, highest overall } \\
\text { accuracy (73.02\%) was seen } \\
\text { in comparison to PP (52.38\%), } \\
\text { MD (50.79\%), MXL (60.37\%), } \\
\text { Fisher (31.75\%) } \\
\text { and K-NN (50.79\%) }\end{array}$ \\
\hline $\begin{array}{c}\text { WV-2 } \\
{[33]}\end{array}$ & $\begin{array}{l}\text { São Luís, Brazil. } \\
\text { (Classification of } \\
\text { Mangrove Areas) }\end{array}$ & OOC & $\begin{array}{l}8 \text { [Streets, Tidal flat, Tidal channel, } \\
\text { ceramic roof, asbestos roof, metal } \\
\text { roof, mangroves, no-mangroves] }\end{array}$ & $\begin{array}{c}\text { Kappa index value of } 0.93 \\
\text { was found for the generated maps }\end{array}$ \\
\hline $\begin{array}{l}\text { WV-2 } \\
{[34]}\end{array}$ & $\begin{array}{l}\text { Zhengzhou city, } \\
\text { China. } \\
\text { (Urban land cover) }\end{array}$ & OOC & $\begin{array}{l}5 \text { [Vegetation, water, road, } \\
\text { building, space land] }\end{array}$ & $\begin{array}{c}84.3144 \% \\
\text { Карра }=0.7807\end{array}$ \\
\hline $\begin{array}{c}\text { SPOT } \\
{[35]}\end{array}$ & $\begin{array}{l}\text { Central-north Poland. } \\
\text { (Land cover mapping) }\end{array}$ & $\begin{array}{l}\text { Rule-based } \\
\text { classification-OOC } \\
\text { approach }\end{array}$ & $\begin{array}{l}13 \text { [Continuous built-up land, } \\
\text { discontinuous built-up land, } \\
\text { industrial units, construction sites, } \\
\text { green urban areas, arable land, } \\
\text { grasslands, gardens, coniferous } \\
\text { forests, deciduous forests, mixed } \\
\text { forests, deforestations and water] }\end{array}$ & $\begin{array}{l}\text { Overall accuracy-89.1\% } \\
\text { Kappa coefficient- } 0.87\end{array}$ \\
\hline
\end{tabular}

Table 3. Tabular representation of comparative study of information extraction procedures.

\begin{tabular}{cccl}
\hline Satellite Image & Study Area & Classifiers & Results \\
\hline $\begin{array}{c}\text { Landsat ETM + and } \\
\text { Terra ASTER [25] }\end{array}$ & $\begin{array}{c}\text { Istanbul, } \\
\text { Turkey }\end{array}$ & MXL and ANN & $\begin{array}{l}\text { MXL algorithm dominated road class over the } \\
\text { image whilst ANN classifier was slightly } \\
\text { sensitive to inland water class. }\end{array}$ \\
Landsat 7 & $\begin{array}{c}\text { Ayvalik district, } \\
\text { Turkey }\end{array}$ & PP, MD and MXL & MXL gave better results than MD and PP. \\
ETM + [36] & Saudi Arabia & $\begin{array}{c}\text { ISODATA, MXL, } \\
\text { MhD and MD }\end{array}$ & $\begin{array}{l}\text { MXL method gave the best results while both } \\
\text { MD and MhD methods overestimated } \\
\text { angriculture land and suburban areas }\end{array}$ \\
\hline
\end{tabular}




\section{Continued}

\begin{tabular}{|c|c|c|c|}
\hline $\begin{array}{l}\text { WV-2 } \\
{[38]}\end{array}$ & $\begin{array}{l}\text { Larsemann Hills, } \\
\text { Antarctica }\end{array}$ & $\begin{array}{l}\text { SVM, MXL, NNC, } \\
\text { SAM and Winner } \\
\text { Takes All (WTA) }\end{array}$ & $\begin{array}{l}\text { Results indicate that the WTA integration and } \\
\text { the SVM classification methods were more accurate } \\
\text { than the MXL, NNC, and SAM classification methods. }\end{array}$ \\
\hline $\begin{array}{l}\text { QB and WV-2 } \\
\text { [39] }\end{array}$ & São Paulo, Brazil & $\begin{array}{l}\text { DT, RF, SVM, } \\
\text { Regression } \\
\text { tree (RT) }\end{array}$ & $\begin{array}{l}\text { RF achieved the highest accuracy }(\kappa=0.95) \text {, } \\
\text { followed either by the RT ( } \kappa=0.85) \text { or the DT } \\
(\kappa=0.77) \text {. The SVM, maybe due to the high } \\
\text { dimensionality and over-fitting issues, } \\
\text { was the algorithm that performed the worst. }\end{array}$ \\
\hline $\begin{array}{l}\text { GE-1 and WV-2 } \\
\text { [28] }\end{array}$ & $\begin{array}{l}\text { Cuevas del } \\
\text { Almanzora, } \\
\text { southern Spain }\end{array}$ & OOC-NN and SVM & $\begin{array}{l}\text { The overall accuracy attained by applying NN and SVM } \\
\text { to the four MS bands of GE-1 were very similar } \\
\text { to those computed from WV-2, for either four or } \\
\text { eight MS bands. The best overall accuracy values } \\
\text { were close to } 90 \% \text {, and they were not improved } \\
\text { by using multi-angle ortho-images. }\end{array}$ \\
\hline $\begin{array}{l}\text { GE-1 and QB } \\
{[27]}\end{array}$ & $\begin{array}{l}\text { Fredericton, } \\
\text { Canada }\end{array}$ & FM and $\mathrm{CM}$ & $\begin{array}{l}\text { The overall accuracies using FM stand higher than } \\
\text { those of CM. The overall accuracy and kappa } \\
\text { coefficient for QB image classification was } \\
\text { better than that of the GE-1 image. }\end{array}$ \\
\hline $\begin{array}{l}\text { IKONOS } \\
\quad[40]\end{array}$ & Tanzania & $\begin{array}{l}\text { OOC using } \\
\text { mathematical and } \\
\text { morphology analysis }\end{array}$ & $\begin{array}{l}\text { OOC based on multi-resolution segmentation and } \\
\text { mathematical morphology analysis procedures } \\
\text { performs best with a spatial accuracy above } \\
85 \% \text { and a statistical accuracy above } 97 \% \text {. }\end{array}$ \\
\hline $\begin{array}{c}\text { SPOT } \\
{[41]}\end{array}$ & Nile river, Egypt & $\begin{array}{l}\text { Contextual classifier, } \\
\text { MXL and MD }\end{array}$ & $\begin{array}{l}\text { The MXL classifier yielded the best classification } \\
\text { accuracy (up to 97\%) compared to the other two classifiers. }\end{array}$ \\
\hline $\begin{array}{l}\text { SPOT and } \\
\text { Landsat TM } \\
\quad[42]\end{array}$ & $\begin{array}{l}\text { Northern Territory } \\
\text { Tropical Savanna, } \\
\text { Australia }\end{array}$ & $\begin{array}{l}\text { Supervised image } \\
\text { classification with and } \\
\text { without ancillary } \\
\text { data-NDVI, DEM, } \\
\text { slope model \& hydrology. }\end{array}$ & $\begin{array}{l}\text { The producer accuracy on average ( } 40 \% \text { ) was higher } \\
\text { for the image classification (without ancillary data) } \\
\text { and a marginal difference in user accuracy ( } 5 \% \text { ). } \\
\text { For the integrated approach (image plus ancillary data) } \\
\text { producer and user accuracies were } 34 \% \text { and } 35 \% \text { respectively. }\end{array}$ \\
\hline $\begin{array}{l}\text { IRS LISS III } \\
{[43]}\end{array}$ & East Sikkim, India & $\begin{array}{l}\text { BAN and hybrid } \\
\text { classification. }\end{array}$ & $\begin{array}{l}\text { Overall accuracy was found to be } 90.53 \% \text { using } \\
\text { the BAN classifier and } 91.57 \% \text { using the Hybrid classifier. }\end{array}$ \\
\hline $\begin{array}{c}\text { GE-1 } \\
{[26]}\end{array}$ & Beijing, China. & BAN and NBC & $\begin{array}{l}\text { The best mean overall classification accuracy } \\
\text { is } 86.2 \% \text { (BAN). As expected, BAN gives } \\
\text { better classification results than NBC. }\end{array}$ \\
\hline $\begin{array}{c}\text { WV-2 } \\
{[44]}\end{array}$ & $\begin{array}{l}\text { University Putra, } \\
\text { Malaysia }\end{array}$ & $\begin{array}{l}\text { OOC including fuzzy } \\
\text { rule-based and SVM }\end{array}$ & $\begin{array}{l}\text { Classification result of supervised SVM contained } \\
\text { mixed objects and misclassifications of impervious } \\
\text { surfaces and other urban features. Rule-based classifier } \\
\text { (overall accuracy = 93.07\%) performed better than } \\
\text { supervised SVM (overall accuracy }=85.02 \% \text { ) resulting in } \\
\text { finer discrimination of spatially and spectrally similar objects. }\end{array}$ \\
\hline
\end{tabular}

shape and relations to adjacent regions. Many studies have been performed comparing the PBC and OOC approach [46]-[50].

On comparing PBC and OOC methods, Xiaoxia et al. [46] concluded that the overall accuracy improved from $63 \%$ to $83 \%$ by using PBC. The reason being not a single pixel can offer significant semantic information which is necessary to interpret an image. OOC techniques are a perfect classification approach, especially for HR imager. Whiteside and Ahmad [47] compared the results of an OOC to a supervised PBC for mapping land cover in the tropical north of the Northern Territory. While both methods produced aggregations of pixels based on land cover classes, the OOC yielded multi-pixel features whereas the PBC contained many small groups of pixels or individual pixels. This produced classes with mixed clusters of pixels as displayed by the heterogenic nature of the image. An evaluation of the results showed the better overall accuracy of the OOC over the PBC. This OOC method provided results with acceptable accuracy; indicating that OOC has great potential for extracting land cover information from satellite imagery captured over tropical Australia. According to Marangoz et al. [48], classification based on traditional PBC approaches to image analyses is limited nowadays. The author implemented OOC in order to overcome the limitations. Based on the overall accuracy values, OOC approach produced more accurate results than PBC. By comparing with on-screen digitizing results, it was seen that many 
buildings cannot be extracted shapely using the PBC approach. On the other hand, these objects were extracted easily using OOC approach. Riggan and Weih [49] also compared an OOC procedure with a traditional PBC methodology (supervised classification) by applying it to medium-spatial resolution satellite imagery merged with HR aerial imagery. They utilized two MS SPOT-5 satellite images, leaf-on and leaf-off, merged with a color infrared aerial image. Because of the correlation between some of the bands of the merged image, principal component analysis (PCA) was used to reduce redundancy in the data. Results indicated that the overall accuracy of the OOC was $82.0 \%$, while that of PBC yielded $66.9 \%$. Thus, almost all the studies that were performed for the comparison of PBC and OOC revealed that OOC suits best for the classification of the HR RS data.

Classification of RS data using PBC in mountainous terrain is challenging because of variations in the sun illumination angle, on the other hand, OOC can utilize GIS tools for improvement of classification results. Gholoobi et al. [50] used PBC and OOC approaches and supplemented GIS concepts and ancillary data for refining of classification results. The results showed that OOC has higher accuracy than PBC. In the traditional classification of MS data, the MXL classifier was considered to provide the best results since it takes into consideration the shape, size, and orientation of a cluster. Traditional image classification methods tend to undergo shortcomings because of non-uniformity of the distribution of the training samples. Land use classification can be further refined by using elevation data in areas with high topographic variation, e.g. mountainous region. Expert knowledge of the area and ground reference data can considerably improve classification accuracy. Results show that an integration of RS and spatial analysis functions in GIS improves the overall classification result from 50.12\% to $74.38 \%$ (24\% increase). But in OOC, the author has tried to model same knowledge that was used in PBC approach. Besides in OOC, there was more potential that leads to higher accuracy. However, with these limited features, OOC approach obtained 13\% more accuracy than PBC approach.

\subsection{Advantages of PBC}

Traditional PBC uses a combined spectral response from all training set pixels for a target class. Therefore, the resulting signature comprises spectral responses from a group of different land covers in the training samples, and the classification system merely ignores the impact of mixed pixels [51].

\subsection{Disadvantages of PBC}

1) The traditional PBC method can’t make the best use of the relationship between pixel and pixels around it, which makes the classification results become incoherent, caused “salt \& pepper phenomenon” [34].

2) While proven highly successful with low to moderate spatial resolution data, these pixel-based classifiers have produced unsatisfactory classification accuracies with hyperspatial data [52].

3) Major among these is that a pixel's spatial extent may not match the extent of the land cover feature of interest [53]. It can’t distinguish surface features which have different objects with the same spectral characteristics, and the classification accuracy is not perfect [34].

4) Another common problem, though, and one that is less often considered, is where the object of interest is considerably larger than the pixel size [53].

5) The failure of PBC techniques is because of the fact that these methods are based on the assumption that individual classes exhibit uniform visual properties. As we increase the spatial resolution of data, the intraclass variation increases and this property of class uniformity is hampered leading to very poor performance [54].

\subsection{Advantages of OOC}

1) Considering the drawbacks of PBC and visual interpretation classification methods, the OBC technology is produced. OOC not only uses spectral information of land types, but also supplements image's spatial position, shape characteristic, texture parameter and the relationship between contexts, which effectively avoid the “salt \& pepper phenomenon” and greatly improve the accuracy of classification [34].

2) Importantly, this object-based information can be integrated with other spatial data in vector-based GIS environments, and used widely in spatial analysis [53].

3) The change of the classification units from pixels to image objects reduces within-class spectral variation and generally removes the so-called salt-and-pepper effects that are typical arise in PBC [55]. 
4) A large set of features characterizing object's spatial, textural, and contextual properties can be derived as complementary information to the direct spectral observations to potentially improve classification accuracy [55].

\subsection{Disadvantages of OOC}

Two types of errors often exist in image segmentation including over-segmentation and under-segmentation. These segmentation errors could affect the subsequent classification process in two ways [55]:

1) Under-segmentation results in image objects that cover more than one class and thus introduce classification errors because all pixels in each mixed image object have to be assigned to the same class.

2) Features extracted from mis-segmented image objects with over-segmentation or under-segmentation errors do not represent the properties of real objects on the Earth's surface (e.g. shape and area), so they may not be useful and could even reduce the classification accuracy if not chosen appropriately.

\section{Applications of HR Satellite Data and Classifiers in Cryospheric Studies}

Classification algorithms are variedly explored in cryosphere for extracting geospatial information for various scientific and logistic applications. One of the most common applications of classification of satellite imageries in cryosphere is to understand temporal changes in geographical phenomena. Some of the case studies are depicted in brief on the basis of satellite data, classifiers, and significant results in Table 4. Low and medium spatial resolution satellite images are frequently used for environmental monitoring in remote, extremely cold areas; however, these satellites cannot provide detailed spatial and spectral information in cryospheric regions [56]. HR and VHR satellite imageries are rarely used for land cover mapping in extremely cold areas, such as the Antarctic. Numerous electro-optical low- and medium-spatial resolution satellite sensors, such as the Landsat series of satellites, the MODIS and the AVHRR, have been successfully used to produce Antarctic land cover maps. Kim et al. [57] classified Antarctic land cover using supervised classification using IKONOS images. The resulting thematic map exhibited low classification accuracy because IKONOS images have only four spectral bands. Kim and Hong [56] mapped rocks, water, vegetation, snow, and ice over Terra Nova Bay, Antarctica. This study used two different types of satellite images acquired during the summer, whereby IKONOS MS (4 m) images were used to classify land cover types. Because a single classification method was inadequate for classifying Antarctic land cover, the authors used a step-by-step approach in which they calculated a normalized difference vegetation index (NDVI), performed a tasseled cap transform, and applied unsupervised ISODATA classification to IKONOS images, after which they achieved a classification accuracy of $\sim 88 \%$.

Jawak and Luis [58] evaluated the potential of 8-band HR WV-2 panchromatic (PAN) and multispectral image (MSI) data for the extraction of polar geospatial information. The authors have mapped the Larsemann Hills of Eastern Antarctica into the three most abundant land cover classes-snow/ice, water bodies, and landmasses, using customized normalized difference spectral index ratios on WV-2 images. An overall accuracy of 95\% to 98\% was achieved with this procedure. Jawak and Luis [38] have also compared four different image classification methods to improve the accuracy of the cryospheric land cover mapping from VHR WV-2 satellite images of Larsemann Hills, east Antarctica. The images on which the authors performed the classification techniques were made up of eight-band MSIs and PAN WV-2 images fused using the hyperspherical color sharpening method. Three classes of land cover—land mass/rocks, water/lakes, and snow/ice-were classified using identical training samples. They used four distinctly different pixel-by-pixel classification methods to classify the WV-2 PAN-sharpened data: a SVM, MXL, NNC, and SAM and then integrated the final thematic land cover map of Larsemann Hills, east Antarctica, using ensemble classification based on a majority voting-coupled WTA approach. The authors integrated results indicated that the WTA integration method and the SVM classification method were more accurate than the MXL, NNC, and SAM classification methods. The overall accuracy of the WTA method was $97.23 \%$ (96.47\% with the SVM classifier) with a 0.96 kappa coefficient (0.95 with the SVM classifier). The accuracy of the other classifiers was $93.73 \%$ to $95.55 \%$ with kappa coefficients of 0.91 to 0.93 . Liu et al. [59] reported the use of Formosat-2 in polar regions during the Polar Imaging Campaign (March 2006 -September 2007). The authors demonstrated applications of Formosat-2 with regard to observing the sea ice condition, monitoring the daily changes in ice shelves, and tracking floating ice. The results indicated that highspatial and temporal resolution Formosat-2 imagery could be a very useful data for cryospheric applications [59]. 
Table 4. Tabular representation of studies showing cryospheric applications of classifiers.

\begin{tabular}{|c|c|c|}
\hline Satellite Data & Classification & Results \\
\hline $\begin{array}{l}\text { WV-2 [60] } \\
\text { Study Area: Greenland }\end{array}$ & $\begin{array}{l}\text { Automated } \\
\text { "spectral-shape" } \\
\text { procedure }\end{array}$ & $\begin{array}{l}\text { Accuracy for detecting actively flowing supraglacial streams, particularly in slushy } \\
\text { areas where classification performance dramatically improves ( } 85.2 \% \text { success) } \\
\text { versus simple threshold methods ( } 52.9 \% \text { and } 59.4 \% \text { success for low and moderate } \\
\text { thresholds, respectively). }\end{array}$ \\
\hline $\begin{array}{l}\text { Landsat TM [61] } \\
\text { Study Area: Weissmies } \\
\text { Group, Switzerland }\end{array}$ & $\begin{array}{l}\text { ISODATA, } \\
\text { MXL }\end{array}$ & $\begin{array}{l}\text { ISODATA clustering depicts that ice and snow in cast shadow are partly unmapped } \\
\text { For MXL, regions in the cast shadow without glacier ice and also the mixed pixels } \\
\text { with ice/snow and terrain along the glacier outline are mapped as a glacier. }\end{array}$ \\
\hline $\begin{array}{l}\text { IRS P6-AWiFS and } \\
\text { TERRA-ASTER [62] } \\
\text { Study Area: Samudra } \\
\text { Tapu glacier, Himachal }\end{array}$ & Supervised MXL & $\begin{array}{l}\text { Overall accuracy of classifications obtained with the use of various band } \\
\text { combinations has been found to range from } 74.72 \% \text { to } 89.35 \% \text {. The highest overall } \\
\text { accuracy (i.e., 89.35\%) resulted from a glacier terrain map derived from a band } \\
\text { combination having two optical and two thermal bands-IB1, IB3, IB6 and IB8. }\end{array}$ \\
\hline $\begin{array}{l}\text { ERS-1 SAR [63] } \\
\text { Study Area: Place Glacier } \\
\text { Basin, western Canada. }\end{array}$ & Supervised MXL & $\begin{array}{l}\text { Kappa coefficients for two images are } 0.49 \pm 0.02 \& 0.48 \pm 0.02 \text {, } \\
\text { respectively, at the } 95 \% \text { confidence level. This represents a classification } \\
\text { accuracy of about } 50 \% \text { for each of the SAR images. }\end{array}$ \\
\hline $\begin{array}{l}\text { Landsat and ASTER [64] } \\
\text { Study Area: Central Alps, }\end{array}$ & $\begin{array}{l}\text { Morphometric } \\
\text { glacial mapping } \\
\text { (MGM) method }\end{array}$ & $\begin{array}{l}\text { A glacier mapping using a TM4/TM5-ratio image in combination with an } \\
\text { MSI analysis to eliminate misclassified pixels was successfully applied to } \\
\text { clean-ice glaciers. MGM was found to be capable to identify supraglacial debris. }\end{array}$ \\
\hline $\begin{array}{l}\text { Landsat and MODIS [65] } \\
\text { Study Area: Antarctica }\end{array}$ & SIRs & $\begin{array}{l}\text { The six-band ETM+ sensor discriminated surface features more sensitive than } \\
\text { those of the two-band AVHRR and MODIS data, which discriminated Blue } \\
\text { Ice Areas (BIAs) from exposed rock and snow. The higher spatial resolution } \\
\text { and better spectral signatures of the ETM+ data improved BIA recognition. }\end{array}$ \\
\hline $\begin{array}{l}\text { Landsat and ASTER [66] } \\
\text { Study Area: } \\
\text { Oberaletschgletscher, } \\
\text { Swiss Alps }\end{array}$ & ANN & $\begin{array}{l}\text { The overall accuracy was } 0.64 \text { with a kappa coefficient of } 0.26 \text {, which is not } \\
\text { satisfactory. In comparison with the independent vector debris layer. The overall } \\
\text { accuracy is } 0.75 \text { and the kappa coefficient is } 0.22 \text {. The performance of } \\
\text { ANN classifier was not convincing. }\end{array}$ \\
\hline $\begin{array}{l}\text { Landsat and IRS LISS III } \\
\text { Study Area: Alam Chal } \\
\quad \text { glacier, Iran [67] }\end{array}$ & SIRs and K-means & $\begin{array}{l}\text { The image of IRS_LISS could not be used for snow mapping due to the } \\
\text { fact that its spectral bands were not appropriate for this application. }\end{array}$ \\
\hline $\begin{array}{l}\text { TERRA SAR-X [68] } \\
\text { Study Area: Juneau } \\
\text { Icefield, Alaska }\end{array}$ & $\mathrm{RF}$ & $\begin{array}{l}\text { Classification of the glacier surface is carried } \\
\text { out with an overall accuracy of } 93.72 \% \text {. }\end{array}$ \\
\hline $\begin{array}{l}\text { WV-2 [58] } \\
\text { Study Area: Larsemann } \\
\text { Hills, East Antarctica }\end{array}$ & CSIRs & $\begin{array}{l}\text { The land-cover map generated from using four CSIR combinations } \\
\text { had a K value ( } 0.98) \text { significantly higher than for the land-cover map } \\
\text { generated using one CSIR combination ( } 0.92) \text {. }\end{array}$ \\
\hline $\begin{array}{c}\text { Landsat [69] } \\
\text { Study Area: Greater } \\
\text { Himalaya Range }\end{array}$ & Supervised MXL & $\begin{array}{l}\text { The overall accuracy of classification performed for the snow- and } \\
\text { ice-covered parts of the glaciers was } 86.29 \% \text { with a Kappa coefficient of } 0.84 \text {. }\end{array}$ \\
\hline $\begin{array}{l}\text { WV-2 [38] } \\
\text { Study Area: Larsemann } \\
\text { Hills, East Antarctica }\end{array}$ & $\begin{array}{l}\text { SVM, MXL, NNC, } \\
\text { SAM and WTA }\end{array}$ & $\begin{array}{l}\text { The overall accuracy of the WTA method was } 97.23 \% \text { ( } 96.47 \% \text { for SVM classifier) } \\
\text { with a } 0.96 \text { kappa coefficient ( } 0.95 \text { with the SVM classifier). The accuracy of the } \\
\text { other classifiers was } 93.73 \% \text { to } 95.55 \% \text { with kappa coefficients of } 0.91 \text { to } 0.93 \text {. }\end{array}$ \\
\hline
\end{tabular}

\section{Factors Affecting Information Extraction}

Several factors affect the accurate information extraction from the RS data. Factors affecting the information extraction accuracy may range from inappropriate satellite data selection, insufficient resolution of the data for extracting a particular information, noise in the satellite data, atmospheric errors, cloud cover in the image and much more. After studying the several cases of information extraction methods, we gathered the information which shows the factors that have affected information extraction approach in a particular study.

Table 5 is a tabular representation of the factors affecting information extraction method in specific studies. Jabari and Zang [27] quoted that, "the main problems in HR image classification are the uncertainties in the 
Table 5. Tabular representation of the factors affecting information extraction method in specific studies.

\begin{tabular}{|c|c|c|}
\hline Satellite Data & Classifiers & Factors Affecting Information Extraction \\
\hline $\begin{array}{l}\text { GE-1 and QB } \\
\text { [27] }\end{array}$ & FM and CM & $\begin{array}{l}\text { The presented method performed quite well in vegetation detection, however, } \\
\text { the CM missed to classify a huge number of segments related to vegetation. } \\
\text { Since this method was very good at detecting vegetation, the overall accuracy } \\
\text { and kappa coefficient for QB image was higher than that of the GE-1 image. }\end{array}$ \\
\hline $\begin{array}{l}\text { GE-1 and } \\
\text { WV-2 } \\
{[28]}\end{array}$ & $\begin{array}{l}\text { OOC analysis-NN } \\
\text { and SVM }\end{array}$ & $\begin{array}{l}\text { Classification algorithms frequently used in OOC approaches, as is the case of NN, do not } \\
\text { perform well on a high-dimensional feature space, due to problems related to feature } \\
\text { correlation. On the whole, NN performed quite well with bare soil, greenhouses and nets, } \\
\text { whereas SVM only outperformed NN in the case of the building class. However, the } \\
\text { performance of SVM when classifying vegetation and orchards was quite poor. The shape } \\
\text { and geometric features (B + Sh), ratios to the scene (B + Rs) and texture features } \\
\text { based on GLCM (B + T) did not contribute to improving the classification. }\end{array}$ \\
\hline $\begin{array}{c}\text { IKONOS } \\
{[29]}\end{array}$ & $\begin{array}{l}\text { Ensemble } \\
\text { Classifiers-DT, ANN, } \\
\text { Adaboost with DT } \\
\text { as base-classifier } \\
\text { and RF, which uses } \\
\text { a CART like DT }\end{array}$ & $\begin{array}{l}\text { Ensemble classifier brought an increase of } 6 \%-12 \% \text {. ANN shows better results where } \\
\text { it outperforms a DT by more than } 8 \% \text {, but only RF has a higher accuracy ( }+4 \%) \text { than ANN. } \\
\text { For all ensemble classifications using DT as the base learner, the computing time is still very } \\
\text { fast even with hundreds of classifiers more. Hence, it would be beneficial to implement } \\
\text { binary strategies with ensemble classifiers. (This, however, does not apply to ANN } \\
\text { for which training costs will be substantially higher and easily become prohibitive). }\end{array}$ \\
\hline $\begin{array}{c}\text { IKONOS } \\
{[30]}\end{array}$ & $\begin{array}{l}\text { SVM, ANN, } \\
\text { MhD, and MXL }\end{array}$ & $\begin{array}{l}\text { Non-parametric methods SVM and ANN performed better than parametric methods } \\
\text { (MXL and MhD), mostly for the less separable and heterogeneous classes. When } \\
\text { classifying complex data sets, SVM and NN appear to be better options because they } \\
\text { don't assume any data distribution while MXL should be used with good results when } \\
\text { the data distribution is Gaussian. Classifications using SVM, ANN or MXL techniques } \\
\text { could be improved by increasing the quantity and quality of training sites. }\end{array}$ \\
\hline $\begin{array}{l}\text { QB } \\
{[31]}\end{array}$ & $\begin{array}{l}\text { Knowledge-based } \\
\text { methods }\end{array}$ & $\begin{array}{l}\text { Suitable training pixels can improve the overall accuracy to } \kappa=0.95 \text {. Mistakes in the } \\
\text { assignment mainly occur with pixels close to the border to the next age class. The use of } \\
\text { knowledge bases and additional data increases the number of separable classes and leads to } \\
\text { better results than simple supervised or unsupervised classifications. A major problem is that } \\
\text { classes which are not considered in the knowledge base will introduce mistakes into the } \\
\text { classification. Usually, most pixels that are assigned as training pixels are classified } \\
\text { correctly and only a negligible minority is misclassified. }\end{array}$ \\
\hline $\begin{array}{l}\text { QB } \\
{[32]}\end{array}$ & $\begin{array}{l}\text { Ensembles } \\
\text { classifier-PP, MD, } \\
\text { MXL, Fisher } \\
\text { and K-NN }\end{array}$ & $\begin{array}{l}\text { The output maps from different supervised techniques had an overall moderate accuracy } \\
\text { with a range from } 41 \% \text { to } 56 \% \text {. Although such results are only moderate by statistical } \\
\text { standards, these are not unrealistic values, especially in RS of marine environments as this } \\
\text { could be caused by a number of factors such as the delay in the time of ground truthing } \\
\text { and the time when the satellite images were taken and the water column correction } \\
\text { algorithm may not remove the effects of water attenuation completely. }\end{array}$ \\
\hline $\begin{array}{l}\text { WV-2 } \\
{[33]}\end{array}$ & OOC & $\begin{array}{l}\text { The result of the scene classified was improved because the attributes related to both } \\
\text { channels Yellow and Red-Edge are better defined, eliminating confusions which occurred } \\
\text { in the past, for instance, with classes Ceramic roof and Bare soil. This is due to the fact that } \\
\text { this channel is positioned spectrally at the absorption end from the red and beginning of the } \\
\text { infrared wavelength for part of the vegetation. So it is partially sensitive to the spectral } \\
\text { behavior of different vegetation types from this region, which was expected for the } \\
\text { spectral bands of this satellite system. }\end{array}$ \\
\hline $\begin{array}{l}\text { WV-2 } \\
{[34]}\end{array}$ & OOC & $\begin{array}{l}\text { The classification method and corresponding classification parameter are low } \\
\text { in flexibility and portability; it is difficult to solve the influence of the shadow } \\
\text { of buildings and crown in classification. }\end{array}$ \\
\hline $\begin{array}{c}\text { SPOT } \\
{[35]}\end{array}$ & $\begin{array}{c}\text { Rule-based } \\
\text { classification-OOC }\end{array}$ & $\begin{array}{l}\text { The overall accuracy of classification was } 89.1 \% \text {. Main misclassifications are due to } \\
\text { confusion with two classes: mixed forests and arable land. The lowest accuracy was } \\
\text { reached for class "gardens"; although producer's accuracy is } 100 \% \text {, user's accuracy } \\
\text { reaches only } 42.5 \% \text {. It means that too many objects were attributed to this class. } \\
\text { In case of this class, the applied classification approach proved to be not sufficient. } \\
\text { It is caused by spectral heterogeneity of class "gardens" and spatial resolution of } \\
\text { SPOT image, which is not adequate for recognizing texture features } \\
\text { formed by relatively small objects. }\end{array}$ \\
\hline
\end{tabular}

position of object borders in satellite images and complex resemblance of the segments to different classes”. Thus, we could conclude that there are several factors which affect the extraction method depending upon satellite data, resolution of the image, reference data, number of classes, spectral bands of the image, shadow effects in the image, object size, pan-sharpening algorithm, re-sampling methods [70] and many more. 


\section{Summary and Discussion}

The classifications are broadly based on PBC approaches or the OOC approaches. Both the methods have their own advantages and disadvantages depending upon their area of application and most importantly the RS datasets that are used for information extraction. Traditional PBC makes use of combined spectral responses from all training set pixels for a given class. Hence, the resulting signature comprises responses from a group of different land covers in the training samples. Thus, this classification system ignores the effect of mixed pixels. PBC approach has many disadvantages when compared to OOC, especially in HR satellite data processing. Though proved to be highly successful with low to moderate spatial resolution data, PBC produced quite a lot unsatisfactory classification accuracy results with hyperspectral data. As PBC approach lacks visual interpretation, OOC approach covers the drawbacks of PBC approach and results in outstanding classification accuracies. OOC can also be integrated with other spatial data in vector-based GIS environments and can be used widely in spatial analysis. After undertaking a complete literature survey, it can be concluded that for HR satellite image classification, OOC approach is considered the most suitable approach by most of the researchers as compared to PBC approach. The traditional PBC approaches cannot make the best use of the relationship between pixel and pixels around it, which makes the classification results, become incoherent, causing "salt \& pepper phenomenon". Though PBC approach is considered very effective for low to moderate spatial resolution data, it is not ideal for HR and VHR satellite data. PBC cannot distinguish surface features which have different objects with the same spectral characteristics. In almost all the case studies, OOC approach resulted in greater accuracy ranging from $84 \%$ to $89 \%$ (approximately).

OOC can, not only use spectral information of land types, but also use images' spatial position, shape characteristic, texture parameter and the relationship between contexts, which effectively avoid the "salt \& pepper phenomenon" and greatly improve the accuracy of classification. Information extraction in cryospheric regions accounts for several difficulties due to very similar spectral responses of the snow and ice, water, and blue ice, rock and shadow, etc. In the case studies performed in cryospheric regions, we can conclude that HR RS data is the best fit for the information extraction. CSIR [45] [58] [71]-[81], ensemble classifiers [38], RF [68] and spectral-shape approach based on OOC methods [60] are the best suited methods as compared to traditional classification approaches. The accuracy shown by these classifiers ranges between $85 \%$ and $97 \%$ (approximately). Moderate resolution satellite data could show acceptable results in very specific conditions, but the accuracy could not exceed $90 \%$ (approximately) in any of the cases. The supervised classification approach could give the accuracy in between $86 \%$ and $90 \%$ (approximately). The unsupervised classification approach is not at all suitable for snow mapping because of the shadow constraint. Also, an ANN classification approach using moderate resolution satellite data could yield unsatisfactory results for debris mapping. Combining ANN classifier with MS approach and morphometric glacial mapping approach, could yield some optimistic results in debris mapping [66]. Information extraction in cryospheric regions is challenging, accounting to the very similar and conflicting spectral responses of the features present in the region. The spectral responses of snow and ice, water and blue ice, rock and shadow are a big challenge for the pixel-based classifiers. Thus, in such cases, OOC approach is a boon for extracting information from the Cryospheric regions. Also, ensemble classifiers and CSIR proved extremely good approaches for information extraction from cryospheric regions.

\section{Conclusion}

Information extraction from HR and VHR RS data can be best done by the OOC methods, CSIR and by using ensemble classifiers. These classification approaches have given significant accuracy results in the case of HR RS data. Also, mapping of cryospheric regions has not been done much so far using these approaches. Thus, extraction of supraglacial lakes, supraglacial ponds, BIAs, supraglacial streams and dust and debris mapping can be done by utilizing these less explored approaches in HR RS studies. Information extraction using HR RS data lacks the application of the OOC approach in cryospheric regions. There is a need to explore OOC approach in much more detail as it has a lot of advantages over PBC approach.

\section{Acknowledgements}

We acknowledge Dr. S. Rajan, Director, NCAOR for his encouragement and motivation of this research. We acknowledge Dr. T. P. Singh (Director, SIT), Dr. Kanchan Khare (HOD, Department of Civil Engineering, SIT), 
Prof. Sagar Kolekar (SIT), and Prof. Rushikesh Kulkarni (SIT), for their cooperation. We also thank Ms. Prachi Vaidya, India for her constructive comments on the draft version of the manuscript. This is NCAOR contribution No. 15/2015.

\section{References}

[1] Campbell, J.B. and Wynne, R.H. (2011) Introduction to Remote Sensing. 5th Edition. http://www.guilford.com/books/Introduction-to-Remote-Sensing/Campbell-Wynne/9781609181765

[2] Lu, D. and Weng, Q. (2007) A Survey of Image Classification Methods and Techniques for Improving Classification Performance. International Journal of Remote Sensing, 28, 823-870. http://dx.doi.org/10.1080/01431160600746456

[3] Tso, B. and Mather, P.M. (2001) Classification Methods for Remotely Sensed Data. Taylor and Francis Inc., New York. http://dx.doi.org/10.4324/9780203303566

[4] Landgrebe, D.A. (2003) Signal Theory Methods in Multispectral Remote Sensing. John Wiley and Sons, Hoboken. http://dx.doi.org/10.1002/0471723800

[5] Kumar, M. and Singh, R.K. (2013) Digital Image Processing of Remotely Sensed Satellite Images for Information Extraction. Conference on Advances in Communication and Control Systems (CAC2S 2013).

[6] Gong, P. and Howarth, P.J. (1992) Frequency-Based Contextual Classification and Gray-Level Vector Reduction for Land-Use Identification. Photogrammetric Engineering and Remote Sensing, 58, 423-437. http://nature.berkeley.edu/ penggong/PDFpapers/GongPERS92.pdf

[7] Kontoes, C., Wilkinson, G.G., Burrill, A., Goffredo, S. and Megier, J. (1993) An Experimental System for the Integration of GIS Data in Knowledge-Based Image Analysis for Remote Sensing of Agriculture. International Journal of Geographical Information Systems, 7, 247-262. http://dx.doi.org/10.1080/02693799308901955

[8] Foody, G.M. (1996) Approaches for the Production and Evaluation of Fuzzy Land Cover Classification from Remotely-Sensed Data. International Journal of Remote Sensing, 17, 1317-1340. http://dx.doi.org/10.1080/01431169608948706

[9] San Miguel-Ayanz, J. and Biging, G.S. (1997) Comparison of Single-Stage and Multi-Stage Classification Approaches for Cover Type Mapping with TM and SPOT Data. Remote Sensing of Environment, 59, 92-104. http://dx.doi.org/10.1016/S0034-4257(96)00109-5

[10] Aplin, P., Atkinson, P.M. and Curran, P.J. (1999) Per-Field Classification of Land Use Using the Forthcoming Very Fine Spatial Resolution Satellite Sensors: Problems and Potential Solutions. In: Atkinson, P.M. and Tate, N.J., Eds., Advances in Remote Sensing and GIS Analysis, John Wiley and Sons, New York, 219-239.

[11] Stuckens, J., Coppin, P.R. and Bauer, M.E. (2000) Integrating Contextual Information with Per-Pixel Classification for Improved Land Cover Classification. Remote Sensing of Environment, 71, 282-296. http://dx.doi.org/10.1016/S0034-4257(99)00083-8

[12] Franklin, S.E. and Wulder, M.A. (2002) Remote Sensing Methods in Medium Spatial Resolution Satellite Data Land Cover Classification of Large Areas. Progress in Physical Geography, 26, 173-205. http://dx.doi.org/10.1191/0309133302pp332ra

[13] Pal, M. and Mather, P.M. (2003) An Assessment of the Effectiveness of Decision Tree Methods for Land Cover Classification. Remote Sensing of Environment, 86, 554-565. http://dx.doi.org/10.1016/S0034-4257(03)00132-9

[14] Gallego, F.J. (2004) Remote Sensing and Land Cover Area Estimation. International Journal of Remote Sensing, 25, 3019-3047. http://dx.doi.org/10.1080/01431160310001619607

[15] Arbiol, R., Zhang, Y. and Palà, V. (2006) Advanced Classification Techniques: A Review. Proceedings of the ISPRS Commission VII Symposium, Enschede, 8-11 May 2006. http://www.isprs.org/proceedings/XXXVI/part7/PDF/250.pdf

[16] Quackenbush, L.J. (2004) A Review of Techniques for Extracting Linear Features from Imagery. Photogrammetric Engineering \& Remote Sensing, 70, 1383-1392. http://dx.doi.org/10.14358/PERS.70.12.1383

[17] Li, M., Zang, S., Zhang, B., Li, S. and Wu, C. (2014) A Review of Remote Sensing Image Classification Techniques: The Role of Spatio-Contextual Information. European Journal of Remote Sensing, 47, 389-411. http://dx.doi.org/10.5721/EuJRS20144723

[18] Mountrakis, G., Im, J. and Ogole, C. (2011) Support Vector Machines in Remote Sensing: A Review. ISPRS Journal of Photogrammetry and Remote Sensing, 66, 247-259. http://dx.doi.org/10.1016/j.isprsjprs.2010.11.001

[19] Jawak, S.D., Luis, A.J., Panditrao, S.N., Khopkar, P.S. and Jadhav, P.S. (2013) Advancement in Landcover Classification Using Very High Resolution Remotely Sensed 8-Band WorldView-2 Satellite Data. International Journal of Earth Sciences and Engineering, 6, 1742-1749.

[20] Jawak, S.D. and Luis, A.J. (2011) Applications of WorldView-2 Satellite Data for Extraction of Polar Spatial Informa- 
tion and DEM of Larsemann Hills, East Antarctica. International Conference on Fuzzy Systems and Neural Computing (FSNC 2011), Hong Kong, 20-21 February 2011, Vol. 3, 148-151.

[21] Blaschke, T. (2010) Object Based Image Analysis for Remote Sensing. ISPRS Journal of Photogrammetry and Remote Sensing, 65, 2-16. http://dx.doi.org/10.1016/j.isprsjprs.2009.06.004

[22] Blaschke, T., Hay, G.J., Kelly, M., Lang, S., Hofmann, P., Addink, E., Feitosa, R.Q., Van der Meer, F., Van der Werff, H., Van Coillie, F. and Tiede, D. (2014) Geographic Object-Based Image Analysis-Towards a New Paradigm. ISPRS Journal of Photogrammetry and Remote Sensing, 87, 180-191. http://dx.doi.org/10.1016/j.isprsjprs.2013.09.014

[23] Yongxue, L., Manchun, L., Liang, M., Feifei, X. and Shuo, H. (2006) Review of Remotely Sensed Imagery Classification Patterns Based on Object-Oriented Image Analysis. Chinese geographical Science, 16, 282-288. http://dx.doi.org/10.1007/s11769-006-0282-0

[24] Myint, S.W., Gober, P., Brazel, A., Grossman-Clarke, S. and Weng, Q. (2011) Per-Pixel vs. Object-Based Classification of Urban Land Cover Extraction Using High Spatial Resolution Imagery. Remote Sensing of Environment, 115, 1145-1161. http://dx.doi.org/10.1016/j.rse.2010.12.017

[25] Cetin, M., Kavzoglu, T. and Musaoglu, N. (2004) Classification of Multi-Spectral, Multi-Temporal and Multi-Sensor images Using Principal Components Analysis and Artificial Neural Networks: Beykoz Case. Proceedings of 20th Congress of the International Society of Photogrammetry and Remote Sensing, Istanbul, 12-23 July 2004. http://www.isprs.org/proceedings/XXXV/congress/comm4/papers/480.pdf

[26] Bogang, Y. and Yu, X. (2014) Remote Sensing Image Classification of Geoeye-1 High-Resolution Satellite. The International Archives of the Photogrammetry, Remote Sensing and Spatial Information Sciences, ISPRS Technical Commission IV Symposium, Suzhou, 14-16 May 2014, Vol. XL-4, 325.

[27] Jabari, S. and Zhang, Y. (2013) Very High Resolution Satellite Image Classification Using Fuzzy Rule-Based Systems. Algorithms, 6, 762-781. http://dx.doi.org/10.3390/a6040762

[28] Aguilar, M.A., Bianconi, F., Aguilar, F.J. and Fernández, I. (2014) Object-Based Greenhouse Classification from GeoEye-1 and WorldView-2 Stereo Imagery. Remote Sensing 2014, 6, 3554-3582. http://dx.doi.org/10.3390/rs6053554

[29] Cheung-Wai Chan, J., Demarchi, L., Van de Voorde, T. and Canters, F. (2008) Binary Classification Strategies for Mapping Urban Land Cover with Ensemble Classifiers. Proceedings of IEEE International Geoscience and Remote Sensing Symposium (IGARSS), Boston, July 6-11, Vol. 3, 1004-1007.

[30] Gil, A., Yu, Q., Lobo, A., Lourenço, P., Silva, L. and Calado, H. (2011) Assessing the Effectiveness of High Resolution Satellite Imagery for Vegetation Mapping in Small Islands Protected Areas. Journal of Coastal Research, Special Issue 64, 1663-1667.

[31] Clasen, A., Frick, A. and Kleinschmit, B. (2006) Knowledge Based Methods for the Classification of Forest Parameters with QuickBird Data. Proceedings of the 2nd Workshop of the EARSeL SIG on Land Use and Land Cover, Center for Remote Sensing of Land Surfaces, Bonn, 28-30 September 2006, 269-275. http://www.zfl.uni-bonn.de/research/earsel/special-interest-group-on-land-use/269-275_clasen.pdf

[32] Muslim, A.M., David, D., Bachok, Z. and Sabri, W.A. (2011) An Ensemble of Classifiers Approach to Coral Distribution Mapping. 34th International Symposium on Remote Sensing of Environment, Sydney, 10-15 April 2011. http://www.isprs.org/proceedings/2011/isrse-34/211104015Final00286.pdf

[33] Kux, H.J.H. and Souza, U.D.V. (2012) Object Based Image Analysis of WorldView-2 Satellite Data for the Classification of Mangrove Areas in the City of Sao Luis, Maranhao State, Brazil. ISPRS Annals of the Photogrammetry, Remote Sensing and Spatial Information Sciences, I-4, 95-100. http://dx.doi.org/10.5194/isprsannals-I-4-95-2012

[34] Chen, Z., Ning, X. and Zhang, J. (2012) Urban Land Cover Classification Based on WorldView-2 Image Data. IEEE International Symposium on Geomatics for Integrated Water Resource Management, Lanzhou, 19-21 October 2012, $1-5$.

[35] Lewinski, St. and Bochenek, Z. (2008) Rule-Based Classification of SPOT Imagery Using Object-Oriented Approach for Detailed Land Cover Mapping. Proceedings of 28th EARSeL Symposium, Remote Sensing for a Changing Europe, Istanbul, 2-5 June 2008.

http://www.ecognition.com/sites/default/files/1098_lewinski_bochenek_rule_based_classification_of_spot_imagery_fo r landcover mapping.pdf

[36] Akgün, A., Eronat, A.H. and Türk, N. (2004) Comparing Different Satellite Image Classification Methods: An Application in Ayvalik District, Western Turkey. 20th ISPRS Congress Technical Commission IV, Istanbul, 12-23 July 2004, 1091-1097. http://www.isprs.org/proceedings/xxxv/congress/comm4/papers/505.pdf

[37] Al-Ahmadi, F.S. and Hames, A.S. (2009) Comparison of Four Classification Methods to Extract Land Use and Land Cover from Raw Satellite Images for Some Remote Arid Areas, Kingdom of Saudi Arabia. Journal of King Abdulaziz University-Earth Sciences, 20, 167-191. http://dx.doi.org/10.4197/ear.20-1.9 
[38] Jawak, S.D. and Luis, A.J. (2013) Very High-Resolution Satellite Data for Improved Land Cover Extraction of Larsemann Hills, Eastern Antarctica. Journal of Applied Remote Sensing, 7, Article ID: 073460.

[39] Novack, T., Esch, T., Kux, H. and Stilla, U. (2011) Machine Learning Comparison between WorldView-2 and QuickBird-2-Simulated Imagery Regarding Object-Based Urban Land Cover Classification. Remote Sensing 2011, 3, 22632282. http://dx.doi.org/10.3390/rs3102263

[40] Giada, S., De Groeve, T. and Ehrlich, D. (2003) Information Extraction from Very High Resolution Satellite Imagery Over Lukole Refugee Camp, Tanzania. International Journal of Remote Sensing, 24, 4251-4266. http://dx.doi.org/10.1080/0143116021000035021

[41] Shaker, A., Yan, W.Y. and El-Ashmawy, N. (2012) Panchromatic Satellite Image Classification for Flood Hazard Assessment. Journal of Applied Research and Technology, 10, 902-911. http://www.redalyc.org/articulo.oa?id=47425142010

[42] Lewis, D., Phinn, S. and Pfitzner, K. (2012) Pixel-Based Image Classification to Map Vegetation Communities Using SPOT5 and Landsat TM in a Northern Territory Tropical Savanna, Australia. Canadian Journal of Remote Sensing, 38, 5, 570-585. http://dx.doi.org/10.5589/m12-047

[43] Pradhan, R., Ghose, M.K. and Jeyaram, A. (2010) Land Cover Classification of Remotely Sensed Satellite Data Using Bayesian and Hybrid Classifier. International Journal of Computer Applications (0975-8887), 7, 1-4. http://dx.doi.org/10.5120/1295-1783

[44] Hamedianfar, A., Mohd Shafri, H.Z., Mansor, S. and Ahmad, N. (2014) Detailed Urban Object-Based Classifications from WorldView-2 Imagery and LiDAR Data: Supervised vs. Fuzzy Rule-Based. FIG Congress 2014, Engaging the Challenges-Enhancing the Relevance, Kuala Lumpur, 16-21 June 2014.

[45] Jawak, S.D., Raut, D.A. and Luis, A.J. (2015) Iterative Spectral Index Ratio Exploration for Object-Based Image Analysis of Antarctic Coastal Oasis Using High Resolution Satellite Remote Sensing Data. ICWRCOE 2015, Aquatic Procedia, 4, 157-164. http://dx.doi.org/10.1016/j.aqpro.2015.02.022

[46] Sun, X.X., Zhang, J.X. and Liu, Z.J. (2005) A Comparison of Object-Oriented and Pixel-Based Classification Approachs Using Quickbird Imagery. ISPRS Proceedings, XXXVI-2/W25. http://www.isprs.org/proceedings/XXXVI/2-W25/source/A COMPARISON OF OBJECT-ORIENTED AND PIXE L-BASED_CLASSIFICATION_APPROACHS_USING_QUICKBIRD.pdf

[47] Whiteside, T. and Ahmad, W. (2005) A Comparison of Object-Oriented and Pixel-Based Classification Methods for Mapping Land Cover in Northern Australia. Proceedings of SSC2005 Spatial intelligence, Innovation and Praxis: The National Biennial Conference of the Spatial Sciences Institute, Melbourne, September 2005, 1225-1231. http://www.ecognition.com/sites/default/files/273_0168.pdf

[48] Marangoz, A.M., Oruç, M., Karakış, S. and Şahin, H. (2004) Comparison of Pixel-Based and Object-Oriented Classification Using IKONOS Imagery for Automatic Building Extraction-Safranbolu Testfield. Proceedings of the 20th ISPRS Congress, Istanbul, 12-23 July 2004. http://jeodezi.beun.edu.tr/marangoz/files/2013/03/bildiri21.pdf

[49] Riggan Jr., N.D. and Weih Jr., R.C. (2009) A Comparison of Pixel-Based versus Object-Based Land Use/Land Cover Classification Methodologies. Journal of the Arkansas Academy of Science, 63, 145-152. http://libinfo.uark.edu/aas/issues/2009v63/v63a16.pdf

[50] Gholoobi, M., Tayyebi, A., Taleyi, M. and Tayyebi, A.H. (2010) Comparing Pixel Based and Object Based Approaches in Land Use Classification in Mountainous Areas. International Archives of the Photogrammetry, Remote Sensing and Spatial Information Science, Kyoto Japan, Vol. XXXVIII, 789-794. http://www.isprs.org/proceedings/xxxviii/part8/pdf/W08L35_20100302025739.pdf

[51] Lu, D. and Weng, Q. (2004) Spectral Mixture Analysis of the Urban Landscape in Indianapolis with Landsat ETM+ Imagery. Photogrammetric Engineering and Remote Sensing, 70, 1053-1062. http://dx.doi.org/10.14358/PERS.70.9.1053

[52] Sridharan, H. and Qiu, F. (2013) Developing an Object Based Hyperspectral Image Classifier with a Case Study Using WorldView-2 Data. Photogrammetric Engineering \& Remote Sensing, 79, 1027-1036. http://dx.doi.org/10.14358/PERS.79.11.1027

[53] Aplin, P. and Smith, G.M. (2008) Advances in Object Based Image Classification. The International Archives of the Photogrammetry, Remote Sensing and Spatial Information Sciences, Beijing, Vol. 37, 725-728. http://www.isprs.org/proceedings/XXXVII/congress/7_pdf/4_WG-VII-4/45.pdf

[54] Corcoran, P., Winstanley, A. and Mooney, P. (2010) Segmentation Performance Evaluation for Object Based Remotely Sensed Image Analysis. International Journal of Remote Sensing, 31, 617-645. http://dx.doi.org/10.1080/01431160902894475

[55] Liu, D. and Xia, F. (2010) Assessing Object-Based Classification: Advantages and Limitations. Remote Sensing Letters, 1, 187-194. http://dx.doi.org/10.1080/01431161003743173 
[56] Kim, S.H. and Hong, C.H. (2012) Antarctic Land-Cover Classification Using IKONOS and Hyperion Data at Terra Nova Bay. International Journal of Remote Sensing, 33, 7151-7164. http://dx.doi.org/10.1080/01431161.2012.700136

[57] Kim, Y.S., et al. (2010) Development of Site Investigation and Monitoring System for Extreme Cold Region. Korea Institute of Construction Technology. http://nysmac.npolar.no/37-Meeting-Groningen/StatusReports37.pdf

[58] Jawak, S.D. and Luis, A.J. (2013) A Spectral Index Ratio-Based Antarctic Land-Cover Mapping Using Hyperspatial 8-Band WorldView-2 Imagery. Polar Science, 7, 18-38. http://dx.doi.org/10.1016/j.polar.2012.12.002

[59] Liu, C.C., Chang, Y.C., Huang, S., Yan, S.Y., Wu, F., Wu, A.M., Kato, S. and Yamaguchi, Y. (2009) Monitoring the Dynamics of Ice Shelf Margins in Polar Regions with High-Spatial- and High-Temporal-Resolution Space-Borne Optical Imagery. Cold Regions Science and Technology, 55, 14-22. http://dx.doi.org/10.1016/j.coldregions.2008.07.008

[60] Yang, K. and Smith, L.C. (2013) Supraglacial Streams on the Greenland Ice Sheet Delineated from Combined Spectral-Shape Information in High-Resolution Satellite Imagery. IEEE Geoscience and Remote Sensing Letters, 10, 801805.

[61] Paul, F. (2000) Evaluation of Different Methods for Glacier Mapping Using Landsat TM. Proceedings of EARSeL-SIG-Workshop Land Ice and Snow, Dresden/FRG, 16-17 June 2000. http://web.unbc.ca/ bolch/publications/BolcKamp06_GeoRaum.pdf

[62] Shukla, A., Arora, M.K. and Gupta, R.P. (2010) Synergistic Approach for Mapping Debris-Covered Glaciers Using Optical-Thermal Remote Sensing Data with Inputs from Geomorphometric Parameters. Remote Sensing of Environment, 114, 1378-1387. http://dx.doi.org/10.1016/j.rse.2010.01.015

[63] Adam, S., Pietroniro, A. and Brugman, M.M. (1997) Glacier Snow Line Mapping Using ERS-1 SAR Imagery. Remote Sensing of Environment, 61, 46-54. http://dx.doi.org/10.1016/S0034-4257(96)00239-8

[64] Bolch, T. and Kamp, U. (2006) Glacier Mapping in High Mountains Using DEMs, Landsat and ASTER Data. 8th International Symposium on High Mountain Remote Sensing Cartography, La Paz, 21-27 March 2005, 37-48. http://web.unbc.ca/ bolch/publications/BolcKamp06 GeoRaum.pdf

[65] Hui, F., Ci, T., Cheng, X., Scambos, T.A., Liu, Y., Zhang, Y., Chi, Z., Huang, H., Wang, X., Wang, F., Zhao, C., Jin, Z. and Wang, K. (2014) Mapping Blue-Ice Areas in Antarctica Using ETM+ and MODIS Data. Annals of Glaciology, 55, 129-137. http://dx.doi.org/10.3189/2014AoG66A069

[66] Paul, F., Huggel, C. and Kääb, A. (2004) Combining Satellite Multispectral Image Data and a Digital Elevation Model for Mapping Debris-Covered Glaciers. Remote Sensing of Environment, 89, 510-518. http://dx.doi.org/10.1016/j.rse.2003.11.007

[67] Roshani, N., Valadan Zouj, M.J., Rezaei, Y. and Nikfar, M. (2008) Snow Mapping of Alamchal Glacier Using Remote Sensing Data. The International Archives of the Photogrammetry, Remote Sensing and Spatial Information Sciences, Beijing, Vol. XXXVII, 805-808. http://www.isprs.org/proceedings/XXXVII/congress/8 pdf/7 WG-VIII-7/14.pdf

[68] Fang, L., Maksymiuk, O., Schmitt, M. and Stilla, U. (2013) Determination of Glacier Surface Area Using Spaceborne SAR Imagery. International Archives of the Photogrammetry, Remote Sensing and Spatial Information Sciences, ISPRS Hannover Workshop 2013, Hannover, 21-24 May 2013, Vol. XL-1/W1, 105-110. http://dx.doi.org/10.5194/isprsarchives-xl-1-w1-105-2013

[69] Ghosh, S., Pandey, A.C. and Nathawat, M.S. (2014) Mapping of Debris-Covered Glaciers in Parts of the Greater Himalaya Range, Ladakh, Western Himalaya, Using Remote Sensing and GIS. Journal of Applied Remote Sensing, 8. http://dx.doi.org/10.1117/1.JRS.8.083579

[70] Jawak, S.D. and Luis, A.J. (2013) A Comprehensive Evaluation of PAN-Sharpening Algorithms Coupled with Resampling Methods for Image Synthesis of Very High Resolution Remotely Sensed Satellite Data. Advances in Remote Sensing, 2, 332-344. http://dx.doi.org/10.4236/ars.2013.24036

[71] Jawak, S.D. and Luis, A.J. (2014) A Semiautomatic Extraction of Antarctic Lake Features Using WorldView-2 Imagery. Photogrammetric Engineering \& Remote Sensing, 80, 939-952. http://dx.doi.org/10.14358/PERS.80.10.939

[72] Jawak, S.D. and Luis, A.J. (2013) Improved Land Cover Mapping Using High Resolution Multiangle 8-Band WorldView-2 Satellite Remote Sensing Data. Journal of Applied Remote Sensing, 7. http://dx.doi.org/10.1117/1.JRS.7.073573

[73] Jawak, S.D., and Luis, A.J. (2015) A Rapid Extraction of Water Body Features from Antarctic Coastal Oasis Using Very High-Resolution Satellite Remote Sensing Data. ICWRCOE’2015, Aquatic Procedia, 4, 125-132. http://dx.doi.org/10.1016/j.aqpro.2015.02.018

[74] Jawak, S.D., Panditrao, S.N. and Luis, A.J. (2014) Enhanced Urban Landcover Classification for Operational Change Detection Study Using Very High Resolution Remote Sensing Data. ISPRS Technical Commission VIII Symposium, Hyderabad, 9-12 December 2014, The International Archives of the Photogrammetry, Remote Sensing and Spatial Information Sciences, Vol. XL-8, 773-779. http://dx.doi.org/10.5194/isprsarchives-xl-8-773-2014

[75] Jawak, S.D., Khopkar, P.S., Jadhav, S.P. and Luis, A.J. (2013) Customization of Normalized Difference Snow Index 
for Extraction of Snow Cover from Cryospheric Surface Using WorldView-2 Data. Proceedings of AGSE International Conference, 16-19 December, CEPT University, Ahmedabad, AGSE, Germany, 391-398.

[76] Jawak, S.D. and Luis, A.J. (2012) WorldView-2 Satellite Remote Sensing Data for Polar Geospatial Information Mining of Larsemann Hills, East Antarctica. Proceedings of 11th Pacific (Pan) Ocean Remote Sensing Conference (PORSEC), Kochi, 05-09 November 2012, ID: PORSEC2012-24-00006.

[77] Jawak, S.D. and Luis, A.J. (2014) Spectral Bands of WorldView-2 Satellite Remote Sensing Data for Semiautomatic Land Cover Extraction in the Antarctic Environment. XXXIII SCAR and 6th Open Science Conference, Auckland, 25-28 August 2014.

[78] Jawak, S.D. and Luis, A.J. (2014) A Novel Set of Normalized Difference Snow/Ice Index Ratios for Extraction of Snow Cover from the Antarctic Environment Using Very High Resolution Satellite Data. XXXIII SCAR and 6th Open Science Conference, 25-28 August 2014, Auckland.

[79] Jawak, S.D. and Luis, A.J. (2012) Hyperspatial WorldView-2 Satellite Remote Sensing Data for Polar Geospatial Information Mining of Larsemann Hills, East Antarctica. XXXII SCAR and 5th Open Science Conference (OSC), Portland, 13-25 July 2012.

[80] Jawak, S.D. and Luis, A.J. (2011) High Resolution 8-Band WorldView-2 Satellite Remote Sensing Data for Polar Geospatial Information Mining and Thematic Elevation Mapping of Larsemann Hills, East Antarctica. 11th ISAES-2011, 10-16 July 2011, Edinburgh.

[81] Jawak, S.D. and Mathew, J. (2011) Semi-Automatic Extraction of Water Bodies and Roads from High Resolution QuickBird Satellite Data. Proceedings of Geospatial World Forum, PN-263, Hyderabad, 18-21 January 2011, $247-257$. 